\title{
Water conservation and management: case study in Siam University
}

\author{
Pornchai Mongkhonvanit ${ }^{1,{ }^{*}}$, Chanita Rukspollmuang ${ }^{2}$, Nattiga Silalai ${ }^{3}$ and Chanida Phitthayanon $^{4}$ \\ ${ }^{1}$ President, Siam University, 38 Petkasem Rd., Bangwa, Phasi Charoen, Bangkok 10160, Thailand \\ ${ }^{2}$ Vice President, Siam University, 38 Petkasem Rd., Bangwa, Phasi Charoen, Bangkok 10160, Thailand \\ ${ }^{3}$ Head, Sustainable Office, Siam University, 38 Petkasem Rd., Bangwa, Phasi Charoen, Bangkok 10160, Thailand \\ ${ }^{4}$ Faculty of Science, Siam University, 38 Petkasem Rd., Bangwa, Phasi Charoen, Bangkok 10160, Thailand
}

\begin{abstract}
Siam University (SU) is one of the leading Thai comprehensive private universities of which "Sustainability" is one of the main missions. The mission is guided by the concept of "Sustainable Development (SD)" and the principle of "Sufficiency Economy Philosophy (SEP)" bestowed by the late King Rama IX. SU has endorsed many sustainability policies and projects including those concerned with ecosystem and water management system. Our target groups include SU staff and students as well as members in Phasi Charoen district. SU has encouraged water conservation and management policies and practices including reduction of water usage program for quite some time. Although piped water is still mainly used, we have installed automated hand washing taps counting to more than $75 \%$ of total water appliances. Water from the campus natural pond is used and reused for gardening and washing. After this initial stage, we have planned to do more programs concerning water recycling, reuse, and treatment system under the principle of SEP. Considering that our pond and surrounding canals are connected to Phasi Charoen communities, we hope that our water conservation and management system will not only lead to a more sustainable campus but also a more sustainable district.
\end{abstract}

\section{Introduction}

Siam University (SU) is one of Thailand's leading comprehensive private universities focusing on "Employability", "Diversity" and "Sustainability" as the three main pillars. The university was founded in 1965 as the first private Engineering School. We were later upgraded to "Siam Technical College", "Siam Technical University", and "Siam University" in 1973, 1986 and 1989, respectively.

The university comprises of 13 schools and colleges which offer a broad variety of undergraduate, graduate, and lifelong education programs. The International Program was established in 1995 to offer students the opportunity to earn Bachelor's degrees focusing on International Business Administration and Hotel \&Tourism, Service Industry Management. Since the inception, Siam University has produced approximately 80,000 graduates with diversified student body. Our graduates enjoy the same privileges accorded to state university graduates. Our academic collaboration over 100 leading universities and institutions worldwide creates unique possibilities for students who wish to transfer from or to Siam University, or who wish to undertake research projects and graduate studies abroad.

It is our mission to prepare students for their future careers in highly dynamic and globalized environment. We cultivate the sense of ethics and responsibility while respecting different cultures and belief as well as embracing diversity and sustainability. At the same time, we strive to elevate the well-being of our surrounding communities in Phasi Charoen district since SU is the only one university in the area. The university has launched "Sustainability Policy" which is guided by the concept of "Sustainable Development (SD)" and the principle of "Sufficiency Economy Philosophy (SEP)" bestowed by the late His Majesty King Bhumibol Adulyadej or King Rama IX. At present, we have initiated several sustainability policies and projects including those concerned with ecosystem and water management system [1].

\section{Setting and infrastructure of campus}

Siam University is located in Phasi Charoen district within the southwest boundaries of downtown Bangkok, approximately 6 kilometers from Silom, the main financial district of the city. Presently, the campus is about 200 meters from the Bangwa station which is the interchange station of BTS (Bangkok Mass Transit System) and MRT (Metropolitan Rapid Transit). This made it fast and convenient to travel to any part of Bangkok from Bangwa station to Siam Square will take not more than 25 minutes. The BTS is now operating and MRT is due to start in the near future.

Siam University comprises of 21 main buildings with a total floor area of approximately 87,000 square meters. There are two multi-purpose buildings which was graciously given the name by His Majesty King

\footnotetext{
* Corresponding author: pornchai@siam.edu
} 
Bhumibol Adulyades (King Rama IX) as "Chalerm Phra Keit, Royal Jubilee Building and opened by the HRH Crown Prince Maha Vajiralongkorn (King Rama X) and HRH Princess Maha Chakri Sirindhorn respectively. The total campus area is around $64,000 \mathrm{~m} 2$. Within the campus, forest vegetation covers $8,000(12.5 \%$ of total area) and planted vegetation is $4,500 \mathrm{~m} 2(7.03 \%$ of total area). Furthermore, total area on the campus for water sorption besides forest and planted vegetation is approximately $5,500 \mathrm{~m} 2(8.59 \%$ of total area).

\section{Sustainability policy of Siam University}

As mentioned earlier, Siam University embraces the significance of sustainability. We hope to integrate this mission into our teaching, research and community services under our guiding principles of "Sustainable Development (SD)" and "Sufficiency Economy Philosophy (SEP)". We are concern about social, economic, environment as well as energy issues both within the campus and the 54 communities in Phasi Charoen district. It is our belief that becoming "sustainable university" is not meaningful unless we live in a "sustainable district". Hence, our main targets are the 3Ss; namely, students, staff, and surrounding communities (Fig.1).

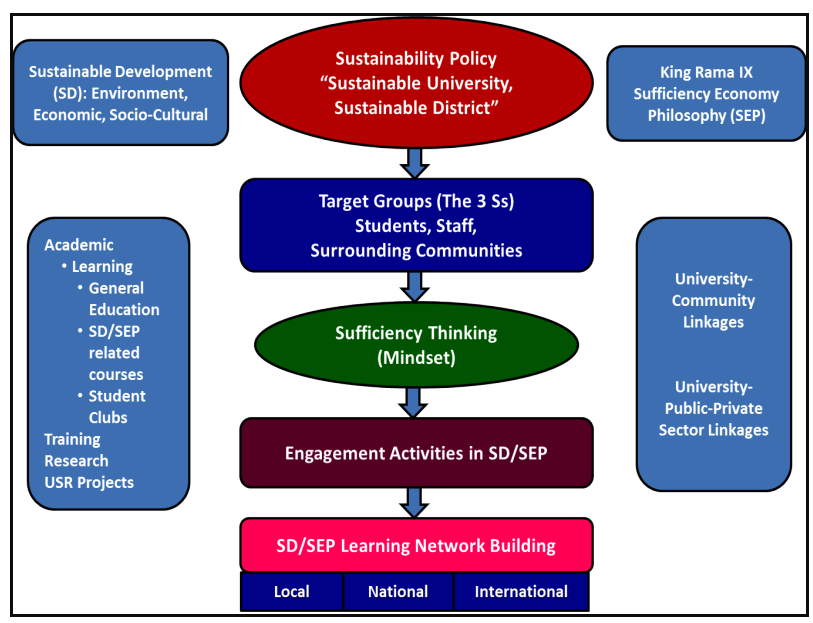

Fig. 1. Sustainability policy and implementation of Siam University

SU has followed footsteps of the great King Rama IX by implementing SEP which aims to create a balanced and stable development, at all levels, from the individual, family and community to society at large by developing the ability to cope appropriately with the critical challenges arising from extensive and rapid changes in the economic, social, environmental, and cultural conditions of the world. Sufficiency has three components: moderation, reasonableness, and prudence, with two foundational conditions: appropriate knowledge and virtues [2].

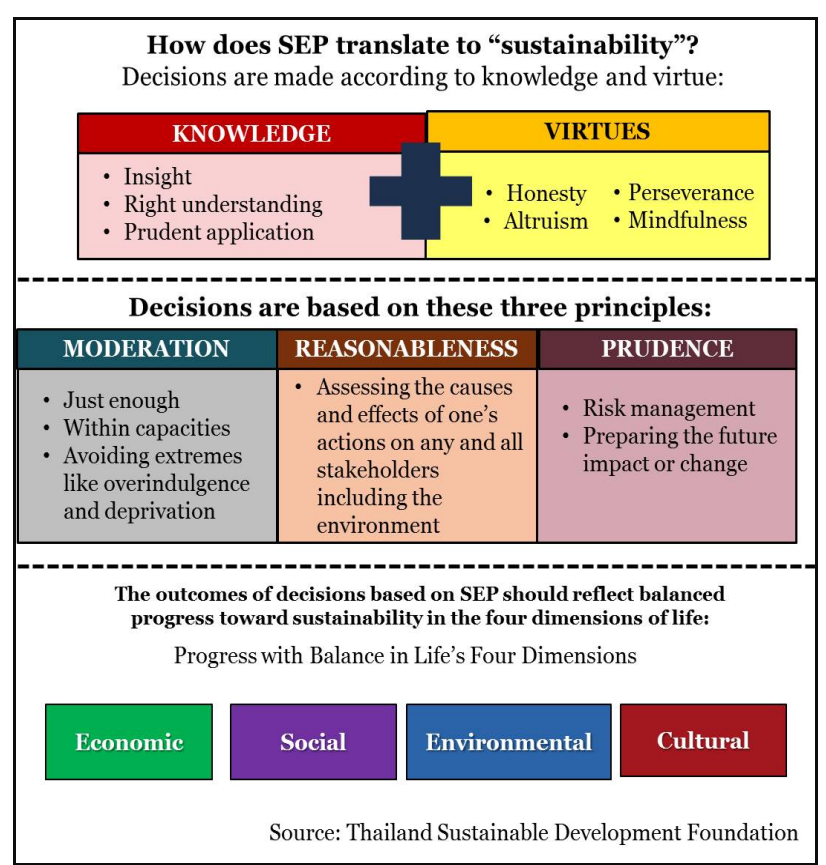

Fig. 2. Translation of SEP to "sustainability"

\section{Ecosystem of Siam University}

SU has followed the guideline of SEP in implementing our sustainability projects, especially the principle of moderation and reasonableness. In addition, we also believe in the interconnectedness of resources and living. All-natural resources including water should be preserved, cared, and shared by all in the campus and in the district. In sum, we can divide our ecosystem into one within the campus and that in our surrounding areas.

\subsection{Ecosystem in Siam University}

With emphasis on water initiatives, Siam University has launched policies and programs such as "Green and Clean Campus" policy with the goal to promote safety and healthy space for a better quality of life for all students and staff. We also committed to develop waste management system for both municipal solid waste and hazardous waste in standard practices and meet regulations. Students and staffs shall be encouraged to reduce reuse recycle and proper management on treatment and disposal. It is our policies that (1) solid waste and hazardous waste shall be managed according to the waste hierarchy of reduction, reuse, and recycle, treatment and responsible disposal, (2) products that can be re-used, or recycled shall be encouraged, and (3) efficient use of equipment, materials or chemicals shall be promoted. SU is fortunate to be located near natural canal and pond. The university benefits from these resources as they help reserve natural rain water for our water supply so that we can at least reduce pipe water usage as well as encourage our water conservation program. We have used and reused water from our natural resources and rain water has been used for gardening and car washing (see Fig. 3 as example). 


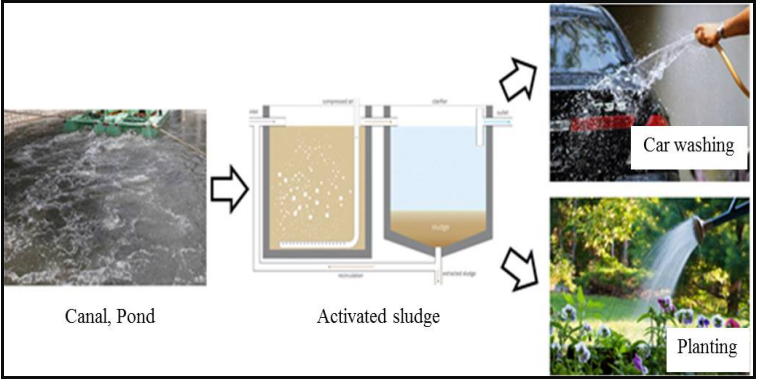

Fig. 3. Recycled water for usage in Siam University

Despite our attempts, because we are situated in a rapidly urbanized area, natural water sources are not enough for all public utilities and we have to depend mostly on pipe water in the campus. Nevertheless, Siam University has started some programs in our main green building and others. Water efficient appliances are installed in order to save water usage. Conventional appliances were replaced by automated hand washing taps (734 points). The usage of automated washing taps is more than $75 \%$ of total water appliances installed as given in Table 1.

Table 1. Water efficient appliance usage.

\begin{tabular}{|l|c|}
\hline \multicolumn{1}{|c|}{ Water Efficient Appliances } & Number \\
\hline Manual washing tap & 234 \\
\hline Automated hand washing tap* & 734 \\
\hline Total & 968 \\
\hline
\end{tabular}

*Automated hand washing tap $=(734$ X $100 / 968)=75.8 \%$

In 2017, plans and programs concerning water conservation and management are as follows:

- Design water treatment system of the ponds to reserve rainwater for usage by applying the principle of "Sufficiency Economy Philosophy (SEP)".

- Install more water efficient appliances such as automated hand washing taps to reduce usage of pipe water.

- Recycle water after treatment for gardening and car washing continuously.

- Campaign water conservation program using posters and online media for all staff and students in the campus.

- Encouraging surrounding communities to participate in water conservation and management activities in order to preserve ecosystem.

Siam University has launched some initial water treatment systems for some time; however, we think that there should be more programs and initiatives so that it will be sufficient for other necessary uses. Thus, it is imperatives that we have clear policy to promote more water and energy conservation and management programs. We envision that other water treatment projects emphasizing the application of appropriate technology to improve water quality will be in use. A designate team is studying the possibility to use
Chaipattana water turbine, King Rama IX's patented design. We also have a future plan to utilize water for clean electricity using hydropower. Within a few years, the following programs shall be promoted:

- Design high efficient water treatment systems of the ponds to reserve rainwater by applying modern procedures in order to get more clean water for usage. - Install other water efficient appliances.

- Design systematic data collection on water management system in order to control piped water usage.

- Launch the initial preparation program for waste water treatment from SU laboratories and other resources before running into nearby canals and other ecosystem.

- Encourage students to participate more in environmental conservation activities such as contest of students' projects concerning environmental management.

\subsection{Ecosystem in the surrounding communities of Siam University}

Siam University pledges to take a leading role in promoting green and clean communities around the campus with the participation of the communities in Phasi Charoen district. Five years ago, SU have established a "Research Centre for Community Development (RCFCD)" with the responsibility to study a long-term research project on "Healthy Space Development: A Pilot Project in Phasi Charoen District, Bangkok", a long-term research project funded by the Thai Health Promotion Foundation [3]. This project is well embraced by community leaders and members as well as related public/private organizations. Among all of the programs undertaken, there are many relating to waste and water management. For instance, "Big Cleaning Day" and canal water treatment project which were participated by community members, Siam University staff and students, members of Phasi Charoen District Administration Office, as well as soldiers and local policemen (Fig.4 and Fig. 5).

In addition, activities proposed by SU staff and projects initiated by students who study courses such as Principle of Economics and the Sufficiency Economy Philosophy, Environmental Management, Life and Environment are encouraged. We hope that by doing these activities, environmental conscience will be cultivated for all our target groups: students, staff, and surrounding communities [4].

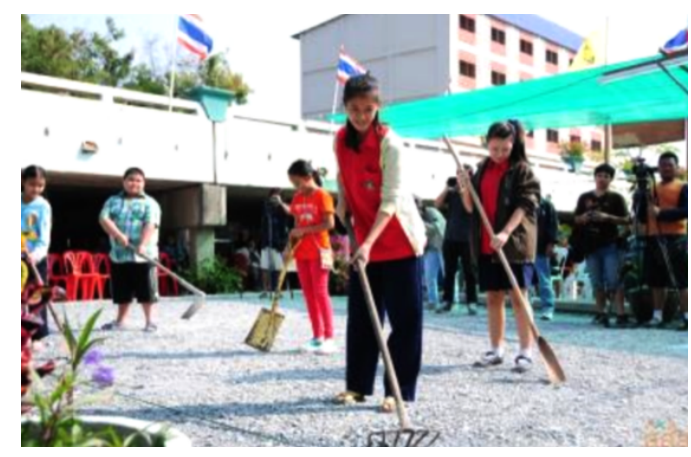




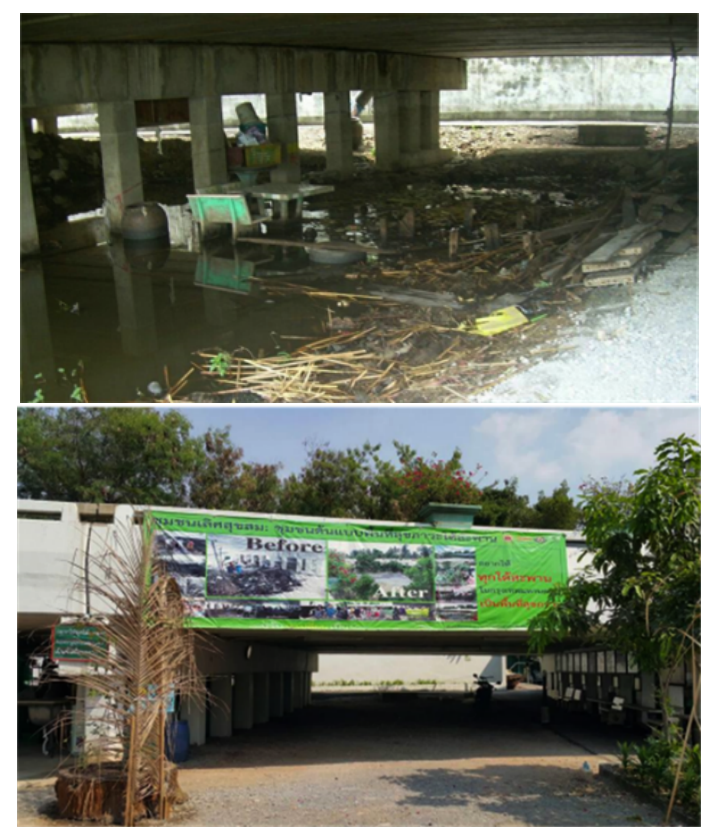

Fig. 4. Big cleaning day: under flyover area management in Lertsooksom community nearby Siam University



Fig. 5. Clean water after treatment in Lertsooksom community's canal nearby Siam University

\section{Concluding Remarks}

Siam University has launched many initiatives to implement our sustainability policies for some time under the guiding principle of "Sustainable Development (SD)" and "Sufficiency Economy Philosophy (SEP)". Our sustainability projects are decided on the principles of moderation, reasonableness, and prudence. With a strong belief in our responsibility to the well-being of everyone in the campus and surrounding areas, the university has endorsed many programs including those concerned with ecosystem and water management system. However, these activities will not be sustained unless all of our target groups (the three Ss) are aware of the necessity and willing to participate. We thus hope that our water conservation and management system will not only lead to a more sustainable campus but also a more sustainable district.

\section{References}

1. Mongkhonvanit, P., Rukspollmuang, C. Sustainable University, Sustainable District: Siam University as a case study, presented at the International Sustainable Campus Network (ISCN) 2017 conference hosted by the University of British Columbia and the City of Vancouver, June 26-28, (2017)

2. Thailand Sustainable Development Foundation, n.d., Thailand Sustainable Development Sourcebook. Available online

http://www.thailandsustainabledevelopment.com/the -book/ (Retrieved 5/16/2016)

3. Chancharoen, K. et al., Research Center for Community Development, Siam University. 2013. Research report on "The context study of urban communities of Phasi Charoen District for healthy space development". (Bangkok: Thanthong Printing, (2013)

4. Rukspollmuang, C., et al., Pathway towards Sustainable University: Policy and Practice of Siam Universit, Paper presented at the 1st Annual Conference of Sustainable University Network (SUN) Thailand, Mahidol University, November 2829 (2016) 